\title{
PENETAPAN KADAR KAFEIN PADA BUBUK TEH HITAM YANG BEREDAR DI PASAR DELI TUA MENGGUNAKAN SPEKTROFOTOMETRI UV
}

\section{Dian Ika Perbina, Christica Ilsanna, Delisma Masauli Simorangkir, Nerdy, Hestika Simarmata}

Fakultas Farmasi Institut Kesehatan Deli Husada Deli Tua e-mail :dianikaperbinameliala@gmail.com

\begin{abstract}
Tea is a drink that is very familiar in the world and is very common in everyday life. Tea is also the most consumed and favored beverage by the public after water. Besides being beneficial, tea also contains compounds that have a negative impact on the body, namely caffeine compounds. Caffeine is an alkaloid of the methylxanthine group which plays a role in increasing the work of psychomotor in the body, and side effects that can be caused are anxiety, irregular heartbeat, difficulty sleeping, tremors, diuresis and others. The purpose of this study was to determine the caffeine content in black tea powder circulating in the Old Deli market. This type of research is descriptive with a purposive sampling method. The analytical method used is qualitative with murexide and quantitative ultraviolet spectrophotometry with a wavelength of $267 \mathrm{~nm}$. The results of a qualitative analysis of all positive samples contained caffeine. The average quantitative yield of caffeine in brand $A$ black tea powder was $(4,82 \pm 0,0356) \%, B$ brand black tea powder $(4,89 \pm 0,0173) \%$ and $C$ brand black tea powder $(4,93 \pm$ $0,0531) \%$. The validation test results obtained linearity $r=0,9984$, $\angle O D$ and $L O Q$ is $0,8074 \mathrm{mcg} / \mathrm{ml}$ and $2,6914 \mathrm{mcg} / \mathrm{ml}, \%$ recovery $=$ $100,07 \%, R S D=0,33 \%$. Based on the results of research conducted, it can be concluded that ultraviolet spectrophotometry can be used to determine caffeine levels in black tea powder.
\end{abstract}

Keywords: Caffeine, Black Tea, Spectrophotometry UV.

\section{PENDAhUluan}

Potensi yang dimiliki Indonesia pada sektor pertanian yang erat hubungannya dengan tiga komponen utama yaitu tanah, tanaman dan iklim/cuaca. Kondisi tersebut bagus untuk membudidayakan tanaman perkebunan seperti teh (Farjina dkk, 2016).

Teh adalah minuman yang sangat familiar di dunia dan sangat umum dalam kehidupan seharihari. Teh berasal dari daun teh muda yang dipetik dari pohonnya (Camelia sinensis). Dewasa ini, teh 
sudah dikemas dengan berbagai bentuk yang menarik (Ningrum dan Murtie, 2013). Produk minuman ini sangat digemari oleh masyarakat, kebanyakan masyarakat mengkonsumsi teh bersamaan dengan makanan (teh sebagai pengganti air). Selain sebagai minuman, teh memiliki khasiat bagi kesehatan tubuh yaitu dapat mengobati sakit kepala, penyubur, diare, astrigen, sariawan, dan menghitamkan rambut, infeksi saluran cerna, kencing manis (diabetes mellitus), membantu menetralkan lemak, serta menurunkan kadar kolesterol dan trigliserida darah tinggi. Namun juga teh memiliki senyawa yang berdampak negatif bagi tubuh yaitu senyawa kafein (Wardani dan Fernanda, 2016; Verawati dkk, 2014).

Kafein merupakan alkaloid dari golongan metilxantin yang memiliki aktivitas farmakologi yang dapat menstimulasi sistem saraf pusat serta serta meningkatkan kerja psikomotor sehingga tubuh tetap terjaga dan memberikan efek fisiologis berupa peningkatan energi. Berdasarkan Surat Keputusan Ka.BPOM No. HK.00.05.23.3644 tentang Ketentuan Pokok Pengawasan Suplemen Makanan (2004), bahwa batas maksimum konsumsi kafein adalah $150 \mathrm{mg} /$ hari. Bila penggunaan kafein dalam sehari melebihi batas maksimum yang dianjurkan, maka dapat menimbulkan efek samping yaitu timbul rasa gelisah, denyut jantung tidak beraturan, sulit tidur, tremor otot, diuresis, tekanan darah tinggi dan dapat menyebabkan ketagihan ringan (Verawati dkk, 2014; Iqbal, 2017; Irawati dkk, 2018).

Berdasarkan uraian diatas, maka perlu dilakukan penelitian untuk memperoleh nilai kadar kafein pada bubuk teh hitam yang beredar dipasar Delitua menggunakan metode spektrofotometri ultraviolet (UV).

\section{METODE}

Metode yang digunakan dalam penelitian ini adalah metode penelitian eksperimental. Jenis penelitian yang digunakan adalah eksperimen semu (Notoadmodjo, 2002).

\section{Alat}

Alat-alat yang digunakan pada penelitian ini yaitu beaker glass dengan berbagai ukuran, corong, corong pisah, erlenmeyer, gelas ukur, hot plate, kertas saring, labu takar, neraca analitik, pipet tetes, pipet volume dan seperangkat spektrovotometer UV-Vis dengan Personal Computer (PC) yang dilengkapi software UV (UV-1800 Shimadzu).

\section{Bahan}

Bahan yang digunakan dalam penelitian ini adalah ammonia, aquadest, asam klorida pekat, baku kafein, hidrogen peroksida, kalsium karbonat, kloroform dan sampel bubuk teh hitam. 


\section{Prosedur Penelitian}

\section{Penyiapan sampel}

Ditimbang 10 gram bubuk teh hitam dimasukkan kedalam beaker glass lalu ditambahkan $100 \mathrm{~mL}$ aquades dan 5 gram $\mathrm{CaCO} 3$ kemudian dididihkan. Kemudian menyaring larutan menggunakan kertas saring (keadaan panas). Filtrat ditampung dalam beaker glass $250 \mathrm{~mL}$. kemudian filtrat diekstraksi dengan menambahkan $30 \mathrm{~mL} \mathrm{CHCl} 3$ didalam corong pisah lalu di gojog hingga membentuk 2 lapisan. Fase $\mathrm{CHCl} 3$ dikumpulkan. Kemudian filtrat ditambah $20 \mathrm{~mL}$ $\mathrm{CHCl} 3$ lalu digojog, fase $\mathrm{CHCl} 3$ dikumpulkan. Kemudian hasil filtrate $\mathrm{CHCl} 3$ digabungkan dan diuapkan (dalam cawan penguap) diatas waterbath sampai fraksi kloroform hilang (Irawati dkk, 2018).

\section{Uji Kualitatif}

\section{a. Uji murexide}

Ditimbang sebanyak $10 \mathrm{mg}$ sampel ditambah $1,5 \mathrm{~mL} \mathrm{H} 2 \mathrm{O} 2$, kemudian ditambahkan 5 tetes $\mathrm{HCl}$ pekat dan dipanaskann diatas penangas air hingga kering dan berwarna kuring, lalu ditambahkan $3 \mathrm{~mL}$ NH3 $6 \mathrm{~N}$. Larutan berwarna merah positif mengandung kafein (Irawati dkk, 2018).

\section{b. Uji parry}

Sejumlah sampel dilarutkan dengan etanol $96 \%$ secukupnya, kemudian ditambahkan reagen parry dan ammonia. Larutan berwarna biru tua/ hijau postif mengandung kafein (Dewi, 2017).
Uji Kuantitatif

Pembuatan larutan induk baku kafein

Ditimbang sebanyak $50 \mathrm{mg}$ baku pebanding kafein, dimasukkan kedalam labu ukur $50 \mathrm{~mL}$. Kemudian diencerkan dengan $\mathrm{HCl}$ $0,1 \mathrm{~N}$ hingga garis tanda dan dihomogenkan, sehingga diperoleh larutan dengan konsentrasi 1000 $\mathrm{mcg} / \mathrm{mL}$ (LIB I). Dari LIB I dipipet 2,5 $\mathrm{mL}$, dimasukkan ke dalam labu ukur $25 \mathrm{~mL}$, kemudian diencerkan dengan $\mathrm{HCl} 0,1 \mathrm{~N}$ hingga garis tanda dan dihomogenkan. Diperoleh larutan dengan konsentrasi 100 $\mathrm{mcg} / \mathrm{mL}$ (LIB II).

Penentuan spektrum serapan maksimum kafein

Diukur absorbansi dengan dipipet 4,3 $\mathrm{mL}$ dari LIB II, kemudian dimasukkan ke dalam labu ukur $50 \mathrm{~mL}$, kemudian diencerkan dengan $\mathrm{HCl} 0,1 \mathrm{~N}$ sampai garis tanda dan diukur serapannya dengan menggunakan spektrofotometri UV pada rentang $\lambda$ $=200-400 \mathrm{~nm}$.

\section{c. Penentuan spektrum serapan kafein}

Dipipet 0,$4 ; 0,6 ; 0,8 ; 1 ; 1,2$ $\mathrm{mL}$ dari LIB II $(100 \mathrm{mcg} / \mathrm{mL})$, dimasukkan kedalam labu ukur 10 $\mathrm{mL}$ dan dicukupkan dengan $\mathrm{HCl} 0,1$ $\mathrm{N}$ sampai garis tanda. Lalu dikocok hingga homogen sehingga diperoleh larutan dengan konsentrasi beruruturut adalah 4, 6, 8, 10 dan 12 $\mathrm{mcg} / \mathrm{mL}$. Masing-masing larutan diukur serapannya pada panjang 
gelombang $200-400 \mathrm{~nm}$.

\section{d. Penentuan kadar sampel}

Ekstrak kafein dimasukkan ke dalam labu takar $100 \mathrm{~mL}$ dan dilakukan pengenceran 10 kali pada labu ukur $10 \mathrm{~mL}$ kemudian diencerkan dengan menggunakan $\mathrm{HCl} 0,1 \mathrm{~N}$ hingga pada garis tanda dan dihomogenkan, kemudian ditentukan kadarnya dengan spektrofotometri UV pada panjang gelombang 200-400 nm (Arwangga dkk, 2016).

\section{HASIL}

\section{Hasil uji kualitatif}

Uji kualitatif kafein pada bubuk teh hitam dilakukan dengan menggunakan dua uji yaitu reaksi murexide dan reaksi parry. Pada uji reaksi murexide hasil yang diperoleh akan memberikan warna merah, sedangkan reaksi parry akan memberikan warna hijau, yang menunjukkan bahwa dari setiap sampel yang diuji positif mengandung kafein.

Tabel 1 Hasil uji kualitatif dengan reaksi murexide

\begin{tabular}{cccc}
\hline No & Sampel & $\begin{array}{c}\text { Hasil } \\
\text { Pengamata } \\
\end{array}$ & $\begin{array}{c}\text { Ke } \\
\mathrm{t}\end{array}$ \\
& & & \\
\hline 1 & Sampel A & Merah & + \\
2 & Sampel B & Merah & + \\
3 & Sampel C & Merah & + \\
\hline
\end{tabular}

Tabel 2 Hasil uji kualitatif dengan reaksi parry

\begin{tabular}{cccc}
\hline No & Sampel & $\begin{array}{c}\text { Hasil } \\
\text { Pengamata } \\
\end{array}$ & $\begin{array}{c}\text { Ke } \\
\mathrm{t}\end{array}$ \\
\hline 1 & Sampel A & Hijau & + \\
2 & Sampel B & Hijau & + \\
3 & Sampel C & Hijau & + \\
\hline
\end{tabular}

Dari Tabel 1 dan 2 dapat disimpulkan sampel yang digunakan dalam penelitian mengandung kafein yang telah diuji secara kualitatif.

\section{Hasil uji kuantitati}

Sampel bubuk teh hitam yang digunakan pada penelitian ini diperoleh dari produk pasar Deli Tua. Sebelum dilakukan penentuan kadar kafein pada sampel, terlebih dahulu dibuat kurva linieritas larutan standar kafein dengan konsentrasi $4,6,8,10,12 \mathrm{mcg} / \mathrm{mL}$. Nilai absorbansi serapan baku pembanding kafein dan kurva persamaan regresi (linieritas) larutan standar kafein ditunjukkan pada Tabel 3 dan Gambar 1 serta hasil penetapan kadar sampel berdasarkan persamaan regresi dapat dilihat pada Tabel 4.

Tabel 3 menjelaskan nilai absorbnsi setiap konsentrasi sampel percobaan. Nilai absorbansi akan dimasukkan ke dalam pesamaan regresi untuk mendapatkan konsentrasi dari kafein.

Dari Gambar 1 dapat dilihat nilai $r$ yang didapatkan adalah 0,9984, sedangkan syarat suatu metode uji mempunyai linearitas 
yang baik jika nilai $r$ lebih besar 0,98 (BPOM, 2009). Hal ini membuktikan bahwa metode ini mempunyai linearitas yang baik.

Dari Tabel 4 dapat dilihat kadar kafei setiap bubuk teh. Kadar bubuk teh paling tinggi ialah bubuk teh $\mathrm{C}$ $(4,93 \pm 0,0531 \%)$. Kadar kafein paling rendah pada bubuk teh $A$ $(4,82 \pm 0,0356 \%)$.

Tabel 3 Nilai serapan baku pembanding kafein

\begin{tabular}{ccc}
\hline No & Kons $(\mathrm{mcg} / \mathrm{mL})$ & Abs \\
\hline 1 & 0 & 0,000 \\
2 & 4 & 0,205 \\
3 & 6 & 0,346 \\
4 & 8 & 0,417 \\
\hline
\end{tabular}

\begin{tabular}{lll}
\hline 5 & 10 & 0,536 \\
6 & 12 & 0,641 \\
\hline
\end{tabular}

Gambar 1 Kurva Linieritas Larutan Standar Kafein

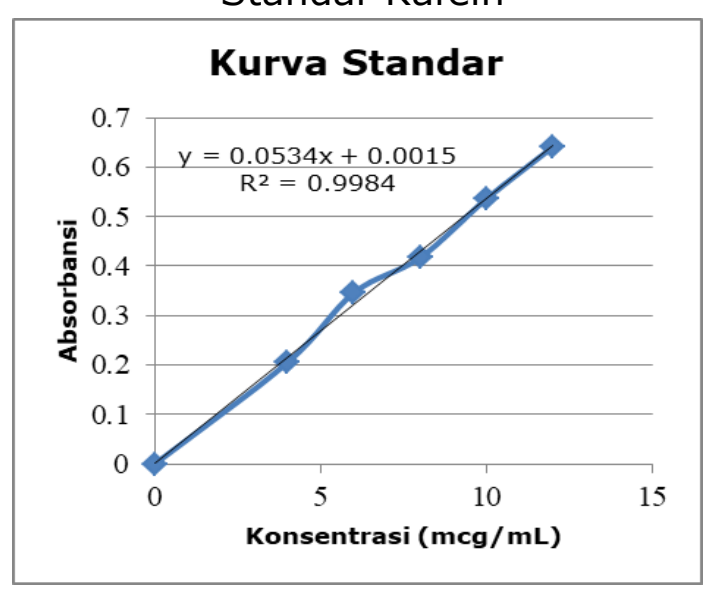

Tabel 4. Penetapan kadar sampel berdasarkan persamaan garis regresi

\begin{tabular}{lccccc}
\hline No & Sampel & Abs. & $\begin{array}{c}\text { C } \\
(\boldsymbol{\mu g} / \mathbf{m l})\end{array}$ & (\%) kadar & $\begin{array}{c}\text { (\%) rata2 } \\
\text { kadar }\end{array}$ \\
\hline 1 & Bubuk Teh & 1,315 & 24,5974 & 4,83 & \\
2 & Merek A & 1,318 & 24,6536 & 4,84 & \\
3 & & 1,309 & 24,4850 & 4,81 & \\
4 & & 1,301 & 24,3352 & 4,78 & $4,82 \pm 0,0356$ \\
5 & & 1,310 & 24,5034 & 4,81 & \\
6 & & 1,314 & 24,5787 & 4,83 & \\
\hline 1 & Bubuk Teh & 1,336 & 24,9906 & 4,91 & \\
2 & Merek B & 1,331 & 24,8970 & 4,89 & \\
3 & & 1,329 & 24,8596 & 4,88 & \\
4 & & 1,332 & 24,9157 & 4,90 & $4,89 \pm 0,0173$ \\
\hline
\end{tabular}




\begin{tabular}{|c|c|c|c|c|c|}
\hline 5 & & 1,331 & 24,8970 & 4,89 & \\
\hline 6 & & 1,332 & 24,9157 & 4,90 & \\
\hline 1 & \multirow{6}{*}{$\begin{array}{c}\text { Bubuk Teh } \\
\text { Merek C }\end{array}$} & 1,324 & 24,7659 & 4,87 & \multirow{6}{*}{$4,93 \pm 0,0531$} \\
\hline 2 & & 1,351 & 25,2715 & 4,96 & \\
\hline 3 & & 1,347 & 25,1966 & 4,95 & \\
\hline 4 & & 1,339 & 25,0468 & 4,92 & \\
\hline 5 & & 1,344 & 25,1404 & 4,94 & \\
\hline 6 & & 1,345 & 25,1592 & 4,94 & \\
\hline
\end{tabular}

\section{Hasil Uji Validasi}

Pada penelitian ini dilakukan uji validasi, membuktikan bahwa parameter tersebut memenuhi persyaratan untuk penggunaanya. Uji yang dilakukan adalah uji presisi, uji akurasi dan penentuan batas deteksi (LOD) dan batas kuantitasi (LOQ). Hasil dari setiap uji yang dilakukan dapat dilihat pada Tabel 5. Pada hasil Tabel 5 didapatkan batas deteksi pada penelitian ini yaitu LOD = 0,8074 dan batas kuantitasi yaitu $L O Q=2,6914$. Menurut Harmita (2014), Batas deteksi adalah jumlah analit terkecil dalam sampel yang dapat dideteksi yang masih memberikan respon signifikan. Sedangkan batas kuantitasi adalah kuantitasi terkecil analit dalam sampel yang masih dapat memenuhi kriteria cermat dan seksama

Tabel 5. Hasil uji validasi

\begin{tabular}{cr} 
& Uji Validasi \\
\hline LOD & 0,8074 \\
LOQ & 2,6914 \\
\% recovery & 100,0000 \\
RSD & 0,3300
\end{tabular}

\section{PEMBAHASAN}

Penetapan kadar kafein pada sampel bubuk teh hitam dilakukan secara kuantitatif menggunakan spektrofotometri ultraviolet (UV). Dimana ekstrak kafein diperoleh dengan menyaring larutan teh dalam keadaan panas yang telah ditambahkan kalsium karbonat dengan menggunakan kertas saring. Kemudian dipisahkan dengan menggunakan corong pisah dengan penambahan kloroform. 
Kalsium karbonat berfungsi untuk memutuskan ikatan kafein dengan senyawa lain, sehingga kafein akan ada dalam basa bebas. Kafein dalam basa bebas akan diikat dengan kloroform, karena kloroform merupakan pelarut pengekstraksi yang tidak bercampur dengan pelarut semula. Kemudian dilakukan pengocokan hingga terdapat dua lapisan yang terbentuk. Lapisan bawah diambil (fase kloroform) dan diuapkan diatas cawan penguap sampai fraksi klorofom hilang dan yang tertinggal hanya ekstrak kafein (Irawati, 2018). Kemudian ekstrak kafein dimasukkan kedalam labu ukur 100 $\mathrm{mL}$ dan dilakukan pengenceran 10 kali pada labu ukur $10 \mathrm{~mL}$ dan ditetukan kadarnya dengan menggunakan spektrofotometri ultraviolet (Arwangga dkk, 2016).

Berdasarkan data yang diperoleh pada Tabel 4, dapat dilihat bahwa dari hasil analisis ada 3 sampel yang diperoleh \% kadar rata-rata kafein masing-masing sampel adalah 4,82 $\pm 0,0356 \%$; $4,89 \pm 0,0173 \%$ dan $4,93 \pm 0,0531 \%$. Hal ini menunjukkan bahwa seluruh sampel bubuk teh hitam memenuhi persyaratan yang sesuai dengan kadar rata-rata pada teh hitam sekitar 1,5\% - 5\% (Sundalian, 2018). Serta dapat dilihat juga kadar kafein (b/b) diperoleh masing-maisng sampel adalah 48,2 mg; 48,9 mg dan $49,3 \mathrm{mg}$. Hal ini juga menunjukkan bahwa sampel memenuhi persyaratan surat keputusan Ka.BPOM No. HK.00.05.23.3644 karena batas maksimum konsumsi kafein adalah $150 \mathrm{mg} /$ hari dibagi dalam 3 dosis.

Menurut Harmita (2014), Batas deteksi adalah jumlah analit terkecil dalam sampel yang dapat dideteksi yang masih memberikan respon signifikan. Sedangkan batas kuantitasi adalah kuantitasi terkecil analit dalam sampel yang masih dapat memenuhi kriteria cermat dan seksama. Pada hasil Tabel 5 didapatkan batas deteksi pada penelitian ini yaitu LOD $=0,8074$ dan batas kuantitasi yaitu $\mathrm{LOQ}=$ 2,6914.

Uji akurasi yang dilakukan denggan menggunakan metode akurasi baku dan diekspresikan dengan menghitung presentase perolehan kembali (\% recovery). Pengujian ini dilakukan dengan membuat suatu seri baku dalam setiap sampel dengan enam kali pengulangan lalu dianalisis menggunakan spektrofotometri ultraviolet. Dimana rata-rata persen recovery memenuhi syarat akurasi untuk jika persen perolehan kembalinya dengan nilai rentang 80\% - 120\% (Harmita, 2004).

Uji presisi dilakukan dengan parameter RSD. Berdasarkan data perhitungan diperoleh harga RSD yang diperoleh yaitu 0,33\%. Dimana syarat RSD tidak boleh lebih dari $2 \%$, dari hasil dapat disimpulkan bahwa penelitian ini memiliki nilai presisi yang baik (Harmita, 2004).

\section{KESIMPULAN}

Berdasarkan penelitian yang telah dilakukan dapat disimpulkan bahwa persen kadar kafein dalam 
bubuk teh hitam yang beredar dipasar delitua dengan merek A sebesar $(4,82 \pm 0,0356) \%$, merek $B$ sebesar $(4,89 \pm 0,0173) \%$ dan merek $C$ sebesar $(4,93 \pm 0,0531) \%$ atau setara dengan kadar kafein dalam mg yaitu 48,2; 48,9 dan 49,3 .

\section{DAFTAR PUSTAKA}

Arwangga, Aryanu Fahmi., Asih, Ida Ayu., \& Sudiarta, Wayan. (2016). Analisis Kandungan Kafein Pada Kopi Di Desa Sesaot Narmada Menggunakan Spektrofotometri Uv-Vis, Jurnal Kimia, Bali. ISSN 19079850, Vol 10(1).

Badan Pengawasan Obat Dan Makanan Republik Indonesia. (2004). Ketentuan Pokok Pengawasan Suplemen Makanan, No.HK.00.05.23.3644, Jakarta. BPOM. (2009). Petunjuk Operasional Penerapan Cara Pembuatan Obat yang Baik. Badan Pengawas Obat dan Makanan Republik Indonesia

Dewi, NV., Fajaryanti, N., Masruriati, E. (2017). Perbedaan Kadar Kafein Pada Ekstrak Biji, Kulit Buah dan Daun Kopi (Cofffea Arabica L.) dengan Metode Spektrofotometri Uv-Vis, Jurnal Farmasetis, Kendal. Vol $6(2)$.

Farjina, A., Jubahar, J., Sabirin, S. 2016. Penetapan Kadar Tanin Pada Teh Celup Yang Beredar Dipasaran

Secara
Spektrofotometri UV-VIS, Jurnal Farmasi Higea, Padang. Vol 8(2).

Harmita. 2004. Petunjuk Pelaksanaan Validasi Metode dan Cara Perhitungannya. Majalah Ilmu Kefarmasian, Dep. Farmasi. FMIPA-UI, Jakarta. Vol. 1 No.3.

Iqbal, AM. 2017. Teh Instan Rendah Kafein dari Teh Hitam, Jurnal Prosiding, Padang.

Irawati, D., Styawan, AA., Nurhaini, R.2018. Penetapan Kadar Kafein Pada Teh Oolong (Camellia sinensis) Dengan Metode Titrasi Bebas Air, Jurnal Urecol, Klaten.

Ningrum, EK., Murtie, M. 2013. Tumbuhan Sakti Basmi Berbagai Penyakit. Cetakan 1, Jakarta Timur: Dunia Sehat. Halaman 58-60

Notoatmodjo, S. (2002). Metodologi Penelitian Kesehatan. Rineka Cipta:Jakarata

Sundalian, Melvia., Nugrahani, Ilma. 2018. Determinasi Kadar Kafein Produk Teh Hitam Indonesia Dengan Menggunakan

Spektrofotometri FTIR. Journal of Pharmaceutical Science and Technology, Bandung. Vol.VII No.1.

Verawati., Harun, S., Satria, B. 2014. Penetapan Kadar Konsumsi Kafein Dalam Minuman Teh Seduhan Yang Beredar Di Pasaran Secara KLT-Densitometri, Jurnal Scientia, Padang. Vol 4(1). 